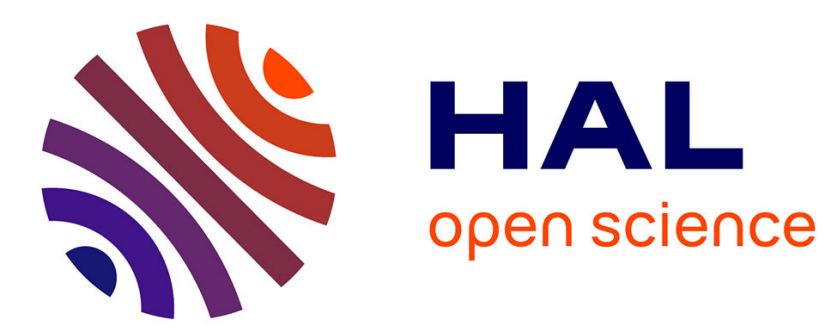

\title{
Supramolecular chemistry in silico
}

Rosemary Sheehan, Peter J. Cragg

\section{To cite this version:}

Rosemary Sheehan, Peter J. Cragg. Supramolecular chemistry in silico. Supramolecular Chemistry, 2008, 20 (05), pp.443-451. 10.1080/10610270701302465 . hal-00513510

\section{HAL Id: hal-00513510 https://hal.science/hal-00513510}

Submitted on 1 Sep 2010

HAL is a multi-disciplinary open access archive for the deposit and dissemination of scientific research documents, whether they are published or not. The documents may come from teaching and research institutions in France or abroad, or from public or private research centers.
L'archive ouverte pluridisciplinaire HAL, est destinée au dépôt et à la diffusion de documents scientifiques de niveau recherche, publiés ou non, émanant des établissements d'enseignement et de recherche français ou étrangers, des laboratoires publics ou privés. 


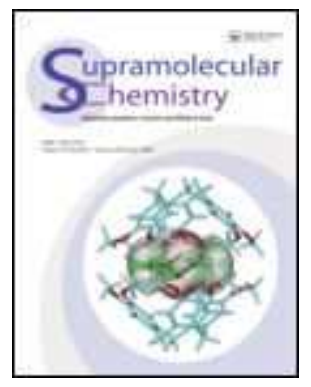

\section{Supramolecular chemistry in silico}

\begin{tabular}{|r|l|}
\hline Journal: & Supramolecular Chemistry \\
\hline Manuscript ID: & GSCH-2006-0075.R2 \\
\hline $\begin{array}{r}\text { Manuscript Type: } \\
\text { Author: }\end{array}$ & Full Paper \\
\hline Keywords: & Supramolech-2007 \\
\hline & $\begin{array}{l}\text { Somplete List of Authors: } \\
\text { Cragg, Peter; University of Brighton }\end{array}$ \\
\hline \multicolumn{2}{|c|}{} \\
\hline $\begin{array}{l}\text { Note: The following files were submitted by the author for peer review, but cannot be converted } \\
\text { to PDF. You must view these files (e.g. movies) online. }\end{array}$ \\
\hline $\begin{array}{l}\text { in silico Fig 1.cdx } \\
\text { in silico Fig 3.cdx }\end{array}$ \\
\hline
\end{tabular}

\section{S ScholaronE \\ Manuscript Central}




\title{
Supramolecular chemistry in silico
}

\author{
ROSEMARY SHEEHAN AND PETER J. CRAGG* \\ School of Pharmacy and Biomolecular Sciences, University of Brighton, Cockcroft \\ Building, Moulsecoomb, Brighton BN2 4GJ, UK
}

\begin{abstract}
Computational protocols capable of modelling supramolecular complexes have been evaluated. The complexation of cations by crown ethers and quaternary ammonium ions by an oxacalix[3]arene are presented as examples. In the latter case reliable qualitative results were obtained using the semi-empirical PM3 method where guest LUMO and electrostatic potential energies have been shown to correlate with experimental binding data. The optimal method for more accurate results combines semi-empirical equilibrium geometry and property calculations with single point energy calculations at the $\mathrm{HF} / 6-31 \mathrm{G}^{*}$ or BP/6-31G* quantum mechanical level.
\end{abstract}

Keywords: Supramolecular complexes; Computational chemistry; Macrocycles

\footnotetext{
*Corresponding author. Tel.: +44 1273 642037. Fax: +44 1273679333 E-mail:

P.J.Cragg@bton.ac.uk
} 


\section{INTRODUCTION}

Supramolecular chemistry is concerned with systems having a level of complexity which in the past would have been the exclusive domain of biologists. Now biologically inspired topics such as molecular recognition, self-assembly and self-replication have become routine areas of study for synthetic chemists. Compounds with the potential to elicit supramolecular phenomena require a substantial degree of a priori design, whether that involves optimising host-guest interactions, binding motif complementarity or geometrical considerations, if they are to function successfully. Given the vast amount of relevant experimental data it would seem reasonable that de novo supramolecular components should be designed using computational methods yet these have not been widely applied to supramolecular systems. In the past the sheer size of most supramolecular aggregates has been prohibitive for molecular modelling studies which have been possible only on dedicated supercomputers. Now, with constant advancement in computer processing power, molecular modelling has become available on desktop machines and in recent years supramolecular chemistry in silico has started to develop as an active area of research. There are, however, still limitations to the levels of theory and the size of structures that can be studied within a reasonable time scale [1].

Applications of computational modelling in the field of supramolecular chemistry are broad in scope. Molecular dynamics simulations have been used to investigate synthetic ionophores and their cation complexes [2,3], the importance of counter ions in alkali and alkaline earth cation extraction by 18 -crown- 6 at the water/sc$\mathrm{CO}_{2}$ interface [4], metal ion selectivity by calix[4]tubes [5], guest binding by calix[4]sulfonate in water [6] and molecular recognition by crown ethers, cryptands and cryptates [7]. Molecular mechanics methods have been applied to oxacalix[3]arene 
conformational analysis [8], the nature of the macrocyclic effect with regard to [18]crown-6 and pentaglyme complexes with $\mathrm{K}^{+}[9]$ and investigations into anion complexation by redox active podands [10]. Cyclodextrin inclusion complexes have been usefully modelled using the semi-empirical PM3 algorithm [11] and a combination of MM2 and PM3 methods [12]. Self-assembly of donor-acceptor aromatic systems has been investigated using MNDO, AM1 and PM3 semi-empirical methods [13]. Frontier orbital maps calculated by PM3 have been used to predict the direction of self-assembly of a novel class of self-organising cucurbituril nanotubes ushering in the possibility of de novo design for molecular wires in nanoelectronics [14]. At a higher level, ab initio quantum mechanical studies have been used to give insights into alkali metal and alkaline earth cation selectivity of [18]crown-6 [15,16], transient alkali metal inclusion in oxacalix[3] arenes [17], the influence of crystal packing on the host-guest interactions of calix[4]arene crystal structures [18], proton tunnelling in calix[4]arenes [19], the impact of cation- $\pi$ interactions on alkali metal binding by calix[4]arenes [20] and ammonium binding by resorcarenes [21]. Also at this higher level of theory, comparisons have been made between GIAO-DFT and experimentally derived complexation-induced chemical shifts of calix[4]arene-solvent inclusion complexes [22].

While this points to a sustained interest in applying computational methods to supramolecular problems it is important to note that many of the molecular simulations require extensive computational resources in terms of hardware, software and time. These resources are often unavailable to synthetic chemists who wish to investigate their supramolecular systems from a computational perspective. Herein we aim to establish a set of computational protocols capable of modelling supramolecular complexes, suitable for use with a desktop computer, to provide valuable insights into 
the nature and behaviour of these systems. Emphasis has been placed upon finding an optimum balance between the levels of theory, from molecular mechanics to ab initio quantum mechanics methods, that can be used for calculations while maintaining practical time scales for these simulations.

\section{EXPERIMENTAL}

\section{Benchmarking}

Structures of [12]crown-4 (1), [15]crown-5 (2), [18]crown-6 (3), [21]crown-7 (4), diazacrowns (5 and 6), dibenzo[18]crown-6 (7) and cryptands (8 and 9), shown in Fig. 1, were constructed and geometry optimised (Hyperchem, MM+). Semi-empirical (PM3) methods were then used to further refine the geometry and obtain $\Delta \mathrm{H}_{\mathrm{f}}$ values. To determine if equivalent methods work equally well when implemented by different commerial sources, the resulting structures were exported and reoptimised (Spartan '04, MMFF followed by PM3). Properties from the PM3 calculations were recorded. Single point calculations at $\mathrm{HF} / 3-21 \mathrm{G}^{*}, \mathrm{HF} / 6-31 \mathrm{G}^{*}$ and $\mathrm{BP} / 6-31 \mathrm{G}^{*}$ levels were then performed using the PM3 geometries. Properties from the quantum mechanical calculations were recorded. Ab initio and semi-empirical results were compared to $\Delta \mathrm{H}_{\mathrm{f}}$ values determined by the Joback method [23]. The results are given in Table 1. Least squares regression lines were plotted for the PM3 and quantum mechanics data to quantify the accuracy of the methods for the macrocycles (Fig. 2). In addition, geometry optimisation calculations of 1 - 9 were also determined at HF/3-21G* and HF/6-31G* levels to determine if more accurate results were obtained.

\section{Macrocyclic complexes of simple cations}

Gas phase modelling of gas phase experimental data 
Models of 1, 2 and $\mathbf{3}$ were subjected to Monte Carlo conformational searching (Spartan). All conformations found by this search method were saved and then optimized by molecular mechanics (MMFF). The lowest energy conformation was selected and used in further calculations (PM3). A centroid was defined relative to the ethereal oxygen atoms. Alkali metal cations were added at the centroid position to form the $1: 1$ complexes $\mathbf{1} \cdot \mathrm{Na}^{+}, \mathbf{1} \cdot \mathrm{K}^{+}, \mathbf{2} \cdot \mathrm{Na}^{+}, \mathbf{2} \cdot \mathrm{K}^{+}, \mathbf{3} \cdot \mathrm{Na}^{+}, \mathbf{3} \cdot \mathrm{K}^{+}, \mathbf{3} \cdot \mathrm{Rb}^{+}$and $\mathbf{3} \cdot \mathrm{Cs}^{+}$. The complexes were geometry optimised (PM3) and resulting energies recorded. Free $\mathbf{3}$ and three complexes, $\mathbf{3} \cdot \mathrm{Na}^{+}, \mathbf{3} \cdot \mathrm{K}^{+}, \mathbf{3} \cdot \mathrm{Rb}^{+}$, were also geometry optimised using a low level $a b$ initio model (HF/3-21G*). Single point calculations were performed for the $\mathrm{Na}^{+}, \mathrm{K}^{+}$and $\mathrm{Rb}^{+}$ions $\left(\mathrm{HF} / 3-21 \mathrm{G}^{*}\right)$ and the output recorded.

\section{Gas phase modelling of solution phase experimental data}

Structures of 1, 2, 3 and 4, and data for $\mathrm{Na}^{+}, \mathrm{K}^{+}, \mathrm{Rb}^{+}$and $\mathrm{Cs}^{+}$guests, were used again. $\mathrm{Sr}^{2+}, \mathrm{Ba}^{2+}, \mathrm{Ag}^{+}, \mathrm{Hg}^{2+}, \mathrm{Pb}^{2+}, \mathrm{NH}_{4}^{+}, \mathrm{NH}_{2} \mathrm{NH}_{3}{ }^{+}, \mathrm{HONH}_{3}{ }^{+}, \mathrm{CH}_{3} \mathrm{NH}_{3}{ }^{+}, \mathrm{CH}_{3} \mathrm{NHNH}_{3}{ }^{+}$and $\mathrm{C}_{2} \mathrm{H}_{5} \mathrm{NH}_{3}{ }^{+}$were geometrically optimised (MMFF). For each cation, a 1:1 3.cation complex was constructed. $\mathbf{1} \cdot \mathrm{Na}^{+}, \mathbf{2} \cdot \mathrm{Na}^{+}$and $\mathbf{4} \cdot \mathrm{Na}^{+} 1: 1$ complexes were also constructed. For all structures where parameters were available, a PM3 optimisation of the free host, guest and complex was performed to generate data for complexes of $\mathbf{1}$ - $\mathbf{4}$ with $\mathrm{Na}^{+}$, $\mathrm{Hg}^{2+}, \mathrm{Pb}^{2+}, \mathrm{NH}_{4}{ }^{+}, \mathrm{NH}_{2} \mathrm{NH}_{3}{ }^{+}, \mathrm{HONH}_{3}{ }^{+}, \mathrm{CH}_{3} \mathrm{NH}_{3}{ }^{+}, \mathrm{CH}_{3} \mathrm{NHNH}_{3}{ }^{+}$and $\mathrm{C}_{2} \mathrm{H}_{5} \mathrm{NH}_{3}{ }^{+}$. The free ions, ligands and complexes were optimised at the BP/6-31G* level. Complexes of $\mathbf{1} \cdot \mathrm{Na}^{+}, \mathbf{2} \cdot \mathrm{Na}^{+}, \mathbf{3} \cdot \mathrm{Na}^{+}$and $\mathbf{4} \cdot \mathrm{Na}^{+}$, and $\mathbf{3}$ with all the listed organic guests were analysed. The resulting PM3 energies were recorded. Density functional (BP/6-31G*) optimisations were performed for $\mathbf{1}-\mathbf{4}$, all crown ether $\cdot \mathrm{Na}^{+}$complexes, and the complexes of 3 with $\mathrm{Na}^{+}, \mathrm{K}^{+}, \mathrm{Rb}^{+}, \mathrm{Cs}^{+}, \mathrm{Sr}^{2+}, \mathrm{Ba}^{2+}, \mathrm{Ag}^{+}, \mathrm{Hg}^{2+}, \mathrm{Pb}^{2+}$ and $\mathrm{NH}_{4}^{+}$. For the free ions, a single point BP/6-31G* calculation was performed and the energy of each recorded. Binding energies calculated using the following formula [24]: 


$$
\Delta \mathrm{E}_{\text {binding }}=\mathrm{E}_{\text {complex }}-\left(\mathrm{E}_{\text {host }}+\mathrm{E}_{\text {guest }}\right)
$$

\section{Oxacalix[3]arene complexes of quaternary ammonium cations}

The $p$-tert-butylhexahomotrioxacalix[3]arene (10) structure, using crystallographic coordinates [25], was imported. One copy of $\mathbf{1 0}$ was retained with its original atomic coordinates and another was geometry optimised (MMFF followed by PM3) to derive the free energy and enthalpy from calculated vibrational frequencies. The vibrational frequencies were inspected to ensure that none were imaginary. A comparative single point $\mathrm{BP} / 6-31 \mathrm{G}^{*}$ calculation was performed for $\mathbf{1 0}$ in the ground state.

Quaternary ammonium iodide guests (Fig. 3, 11 - 17), known to bind to 10 [26], were built. A formal charge of +1 was set on the nitrogen atom of each guest. The lowest energy ground state conformer of each flexible guest was determined from a systematic conformational search. Cations were geometry optimised (PM3) and a potential density surface constructed using single point energy calculations at PM3, $\mathrm{HF} / 6-31 \mathrm{G}^{*}$ and BP/6-31G* levels. For all guest models, an iodide counter ion with a formal charge of -1 was added at a distance of $2.5 \AA$ from the nitrogen atom.

Ground state equilibrium geometries for the ammonium iodide salts were determined at the PM3 level, starting from MMFF (or MMFF conformer) geometry, and vibrational frequencies calculated. A BP/6-31G* single point calculation was performed for each guest. The same structures were used for each host-guest system. Both the guest cation and its counter ion were initially positioned beyond the influence of short-range interactions. Iodide was restrained to $5 \AA$ below the ether oxygen atoms of the host for each system. The nitrogen atom of each guest was constrained to $6 \AA$ above the ether oxygen atoms of the host as the upper rim of $\mathbf{1 0}$ is more sterically hindered than the lower rim in the cone conformation. All initial constraints were 
removed from the complexes and ground state geometry optimisations performed (MMFF then PM3). An example of this is given in Fig. 4. Vibrational frequencies were recorded. After PM3 optimisation, a BP/6-31G* single point calculation was carried out for each complex. Binding energies for the host-guest complexes were calculated using equation (1) as before.

For the optimised host and host-guest complexes, the cone angle was also calculated to indicate the extent of conformational rearrangement undergone by the host molecule during binding. These values are given in Table 2 .

\section{RESULTS AND DISCUSSION}

\section{Benchmarking}

Linear regression of the benchmarking data for simple aromatic systems has shown that $a b$ initio quantum mechanical methods are not always necessary to calculate accurate heats of formation [27]. In our survey $\mathrm{HF} / 3-21 \mathrm{G}^{*}$ single point calculations correlated well with the literature $\left(\mathrm{r}^{2}=0.82\right)$, as did $\mathrm{HF} / 6-31 \mathrm{G}^{*}$ and $\mathrm{BP} / 6-31 \mathrm{G}^{*}$ (both $\mathrm{r}^{2}=0.82$ ) yet the semi-empirical PM3 method was the most consistent $\left(\mathrm{r}^{2}=0.99\right)$ giving a much better balance between computational resource required and level of accuracy [28]. The results were also independent of software package, Hyperchem performing as well as Spartan.

We wished to see if PM3 simulations were as successful when evaluating molecules of relevance to supramolecular chemistry. A set of nine macrocycles, geometry optimised by molecular mechanics, was subjected to semi-empirical and $a b$ initio methods to determine heats of formation. The results showed that, of the semiempirical models, PM3 was the most accurate [28]. A comparison between $\Delta \mathrm{H}_{\mathrm{f}}$ values predicted by semi-empirical, quantum mechanical and density functional theories with those from the Joback method gave $\mathrm{r}^{2}$ values of 0.87 for PM3 and 0.21 for HF/3-21G*, 
$\mathrm{HF} / 6-31 \mathrm{G}^{*}$ and BP/6-31G*. There appeared to be no improvement in the outcome when geometries were calculated by time-consuming ab initio methods $\left(\mathrm{r}^{2}=0.21\right.$ for both HF/3-21G* and HF/6-31G* data [28]) making the semi-empirical PM3 approach the optimum method.

\section{Macrocyclic complexes of simple cations}

Gas phase modelling of gas phase experimental data

Initial geometries were generated using MMFF, a heavily parameterised molecular mechanics system designed to be used in molecular dynamics of proteins in addition to traditional organic systems [29], as it takes account of electrostatic, dipole and hydrogen bonding interactions which are often the driving forces behind supramolecular complex formation. The software packages used had limited PM3 parameters for alkali metals and no $\mathrm{HF} / 3-21 \mathrm{G}^{*}$ parameters for caesium so a limited trial was attempted in which PM3 and BP/6-31G* were compared [28]. The gas phase $\Delta \mathrm{H}_{\text {binding }}$ energies of three crown ether complexes $\left(\mathbf{1} \cdot \mathrm{Na}^{+}, \mathbf{2} \cdot \mathrm{Na}^{+}\right.$and $\left.\mathbf{3} \cdot \mathrm{Na}^{+}\right)$were calculated using equation (1) and compared to experimentally derived dissociation energies [30]. The results were similar, with $\mathrm{r}^{2}=0.84$ for PM3 against 0.83 for BP/6-31G*. In the absence of PM3 parameters a similar analysis, this time keeping the same macrocycle and varying the alkali metal $\left(\mathbf{3} \cdot \mathrm{Na}^{+}, \mathbf{3} \cdot \mathrm{K}^{+}\right.$and $\left.\mathbf{3} \cdot \mathrm{Rb}^{+}\right)$, was undertaken using a low level quantum mechanics model, $\mathrm{HF} / 3-21 \mathrm{G}^{*}$. Here an excellent correlation with dissociation energies was found $\left(\mathrm{r}^{2}=\right.$ 0.99). A density functional treatment at $\mathrm{BP} / 6-31 \mathrm{G}^{*}$ level for $\mathbf{3} \cdot \mathrm{Na}^{+}, \mathbf{3} \cdot \mathrm{K}^{+}, \mathbf{3} \cdot \mathrm{Rb}^{+}$and $\mathbf{3} \cdot \mathrm{Cs}^{+}$gives an equally impressive correlation $\left(\mathrm{r}^{2}=0.99\right)$; if data for $\mathbf{1} \cdot \mathrm{Na}^{+}, \mathbf{1} \cdot \mathrm{K}^{+}, \mathbf{2} \cdot \mathrm{Na}^{+}$ and $2 \cdot \mathrm{K}^{+}$are included this drops marginally to 0.96 [27]. Replication of gas phase experimental data for alkali metal cation binding by crown ethers was therefore largely successful at all levels of theory. 


\section{Gas phase modelling of solution phase experimental data}

Using data calculated for gas phase complexation simulations, and extending the data set to include more inorganic and organic cations, comparisons were made between calculated gas phase binding energies using equation (1) and experimentally derived binding data in methanol or water [31]. PM3 and BP/6-31G* data for $\mathbf{1} \cdot \mathrm{Na}^{+}, \mathbf{2} \cdot \mathrm{Na}^{+}$, 3. $\mathrm{Na}^{+}$and $4 \cdot \mathrm{Na}^{+}$gave good agreement $\left(r^{2}=0.95\right.$ and 0.98 , respectively), however, the extended data set comprising ten cations by 3 calculated to BP/6-31G* level failed to correlate with experimental data $\left(r^{2}=0.53\right)$ [28]. Solvents, unsurprisingly, have an unpredictable effect on binding. This is certainly the case in experimental systems involving polar solvents, polar host molecules and ionic guests as can be seen when comparing supramolecular binding constants obtained in different solvents. The use of explicit solvent was considered as it may have an effect on the structure of the complex that is used in the simulation. Unfortunately such simulations are computationally expensive and probably best used to probe potential structural effects, such as the emergence of hydrogen bonded networks, using molecular mechanics methods [32]. A study of calix[4]arene conformational interconversion using a continuum solvent approach has proved successful although it is unclear how well this method would translate to model the behaviour of a multicomponent host-guest system [33]. We attempted to apply explicit solvation to crown ether complexes but without success [27]. Solvent box molecular dynamics simulations are undoubtedly a much better approach in this regard and have been used to model macrocyclic binding affinities in solution for some time [34] as well as liquid-liquid extraction by macrocycles [35].

\section{Oxacalix[3]arene complexes of quaternary ammonium cations}

Using $-\Delta G^{\text {o }}$ values determined by Masci [26] for quaternary ammonium iodide complexation by oxacalixarene 10, it is possible to determine if any correlations exist 
between computational and experimental data for these simple host-guest systems. Ordinarily a solvated model would be preferable but as the experimental data were derived from NMR binding experiments in a non-coordinating solvent, $\mathrm{CDCl}_{3}$, gas phase models were used.

Experience at the benchmarking stage of this project showed that replication of solvated binding selectivity is not normally achieved without the explicit inclusion of solvent molecules and even then the results are of dubious value. However, the systems of interest here are rather complicated; the host molecule is large and each complex consists of a cation as well as its associated counter ion. The addition of a sufficient number of solvent molecules represents a significant increase in size of the model, and would render higher-level calculations impossible on a desktop computer. Hartree-Fock total energy calculations were prohibitive for the solvated systems, as were gas phase calculations of enthalpy or free energy. Density functional BP/6-31G* energy calculations were attempted for the complexes in vacuo, but could not be completed within a reasonable timescale. PM3 binding energies were not expected to be sufficiently reliable, so a simpler approach was considered; it was hypothesized that certain properties of the isolated guest molecules might be sufficient to predict binding strength. This approach, if successful, would allow significant savings in terms of computational time and processing requirements.

Electrostatic attractions are often vital components of the array of forces responsible for molecular recognition $[33,36]$ so it was decided to determine if experimental selectivity might originate from the relative strength of cation- $\pi$ interactions, or from ion-dipole interactions involving the ether oxygen atoms. Whether binding strength is more related to ion-dipole attractions or to the cation- $\pi$ effect could possibly be estimated by the position of the bound guest in the host molecule; the 
distance from the most acidic protons of the guest to the aromatic rings or the ethereal oxygen atoms of the host may indicate which interaction is most important to complexation. Masci states, "the interaction between the positive charges and the $\pi$ cloud of the aromatic systems can be considered the main driving force for the complexation" [26]. The aromatic regions of oxacalix[3] arene 10, as shown in Fig. 5, would appear to favour guests with trigonal planar, pyramidal or spherical symmetry. This does not necessarily mean, however, that cation- $\pi$ interactions are exclusively responsible for selectivity. In a study of alcohol binding by a resorcinol cyclic tetramer [37], Re and Nagase concluded that even though the dispersion energies responsible for the $\mathrm{CH}-\pi$ interaction provided the majority of the energy of complexation, the selectivity or molecular recognition, was determined by the smaller electrostatic attraction $[38,39]$.

A simple correlation was discovered between guest cation LUMO and $-\Delta \mathrm{G}^{\mathrm{o}}$ which correctly predicted the rank order of the free energy changes: a plot of LUMO energy against $-\Delta G^{\circ}$ shows an $r^{2}$ value of 0.88 (Fig. 6). Experimental selectivity was reproduced; the only discrepancy concerned the complexes $\mathbf{1 0 \cdot 1 3}$ and $\mathbf{1 0 \cdot 1 5}$, which would have been expected to have equal values. Nonetheless they were correctly bracketed between $\mathbf{1 0 \cdot 1 2}$ and 10.14.

If cation- $\pi$ interactions are the principal force in oxacalixarene binding, then a measure of the cation "strength" should be enough to predict relative binding affinity, as long as the $\pi$-system remains constant. Dougherty has shown that the electrostatic component is dominant in cation- $\pi$ binding [40], and successfully used electrostatic potential maps as an indicator of binding strength. In our study it was hoped that the value of greatest positive electrostatic potential for each free guest would be an appropriate measure of how strongly it would be bound by the oxacalixarene host. 
The order observed in the previous LUMO-based study was also observed when electrostatic potential was determined, the $\mathbf{1 0} \cdot 13$ complex again provided the only major inconsistency. It is uncertain why the calculated data for $\mathbf{1 3}$ do not fit experiment though this guest is the only bridged bicyclic ring system among those studied and it may be that its properties are simply too different to usefully compare it to the others. The iodide anions were omitted from this approach so it is also possible that the discrepancy observed for $\mathbf{1 3}$ was due to an experimental effect of the counterion. Linear regression for the data gives a fit of 0.86 (Fig. 6); removal of the outlying value for $\mathbf{1 0} \cdot \mathbf{1 3}$ improves this to 0.99 .

In the absence of crystal structures the computationally generated geometries can give insights into the likely importance of different intermolecular forces. Thus, in the example chosen, the positioning of the guest molecules suggests that the cation- $\pi$ interaction may be of primary importance, but ion-dipole interactions can also contribute to overall complex stability. In each case, the iodide counterion was observed to associate with the lower rim of the oxacalixarene after optimisation. Given that iondipole interactive forces are typically stronger than cation- $\pi$ interactions (12 - 50 $\mathrm{kcal} / \mathrm{mol}$ compared to $1-20 \mathrm{kcal} / \mathrm{mol}$ [41]), they could provide a significant stabilisation effect. The results showed that each of the quaternary ammonium iodide guests was bound within the oxacalix[3]arene cavity, thus qualitatively supporting the literature findings. In each case, the host molecule was significantly rearranged in order to accommodate the guest, with the initial shallow cone structure of the oxacalixarene closing around the guest to maximise favourable interactions. This relationship, however, was not reliable enough to use a predictor of binding strength. Factors such as the steric bulk of the guest would be expected to influence the rearrangement potential 
of the host, with large guests reducing the degree to which the host can close around them, despite favourable interactions.

\section{CONCLUSIONS}

To make a computational protocol widely applicable it must be simple to use and require a level of resource within reach of most researchers. Herein we have shown that a combination of molecular mechanics and semi-empirical methods can adequately describe some simple host-guest complexes. These methods are to be found within many chemical software packages and do not necessitate extensive knowledge of computational techniques by the researcher. In general we have shown that the low level PM3 calculations perform well across a diverse group of macrocycles. The consistency of the PM3 method makes it preferable to the more time consuming ab initio quantum mechanics and density functional methods where isolated macrocyclic host molecules are concerned. Where exact energies are required, the geometries generated by MMFF/PM3 optimisations are accurate enough for higher level single point calculations to give good results. This avoids extremely lengthy geometry optimisations using $a b$ initio methods.

Replication of gas phase experimental data for alkali metal cation binding by crown ethers was largely successful. For the small data set studied, PM3 calculations reproduced experimental selectivity marginally better than the $\mathrm{BP} / 6-31 \mathrm{G}^{*}$ level. At the $\mathrm{HF} / 3-21 \mathrm{G}^{*}$ level binding selectivity was also reproduced and the correlation with experiment was excellent. This extended to a larger data set comprising eight 1:1 crown ether - alkali metal cation complexes investigated at the BP/6-31G* level. The initial conformation of the free host molecule was relatively unimportant, as long as it had an energy minimised geometry. However, when a host - guest supramolecule was used as 
the basis for a simulation, the structure required full geometry optimisation if inconsistent results were to be avoided.

The treatment of solvated systems was an issue which we were unable to address. Dougherty [36] argued that differential solvation-desolvation effects will be minor if the ion is held constant while the neutral host is varied, and that gas phase calculations may therefore be of value for prediction of solution phase binding preferences. Our use of explicit microsolvation did not correlate with experimental data [27]. Molecular dynamics simulations in solvent boxes have proved to be successful and undoubtedly offer the most promise $[34,35]$.

For the oxacalix[3]arene example, gas phase binding energies and enthalpies calculated at the PM3 level show qualitative support for experiment. Although these correlations were not good enough to reproduce the exact experimental order of selectivity, both $\Delta \mathrm{E}$ and $\Delta \mathrm{H}$ seem capable at least of distinguishing between groups of guests which are very weakly bound, and groups which are more strongly bound. By way of contrast, calculated $-\Delta \mathrm{G}^{\circ}$ values showed no agreement with the literature, whether qualitative or quantitative.

The study of isolated guest molecule properties using PM3 calculations gave unexpected results. Indeed, the magnitudes of the LUMOs and electrostatic potentials of the guest molecules provided the best correlation with experimental selectivity. It may be that calculations of these properties are more accurate than energy calculations at a semi-empirical level of theory as only valence electrons are considered. This should provide an adequate representation of both frontier molecular orbital energy and electrostatic potential but might not be expected to perform so well for energetic quantities such as heat of formation, or total energy, which concern the nuclei and inner electrons as well as those in the valence shell. 
The optimal protocol, balancing computational time and accuracy, was to use PM3 equilibrium geometry and property calculations as a starting point (where parameterisation was available), and to follow these with single point energy calculations at the $\mathrm{HF} / 6-31 \mathrm{G}^{*}$ or $\mathrm{BP} / 6-31 \mathrm{G}^{*}$ level. If a qualitative answer is all that is necessary then PM3 alone will suffice. Where further structural knowledge is required, geometry optimisation using the $6-31 \mathrm{G}^{*}$ basis set may be performed, but it has a significantly greater computational cost.

It is clear that there are potential pitfalls when modelling supramolecular complexes in silico but we have shown here that even PM3 semi-empirical calculations can give an adequate first guess as to the nature and strength of supramolecular interactions, providing insights that could be used to direct synthesis. In terms of accuracy, as well as computational time, it does not appear to be worth exceeding this level of theory unless a high level basis set $\left(6-31 \mathrm{G}^{*}\right.$ as a minimum) is used.

\section{Acknowledgements}

RS thanks the EPSRC for a DTA studentship and the University of Brighton for use of software.

\section{References}

[1] Hehre, W. J.; Yu, J.; Klunzinger, P. E.; Lou, L. A Brief Guide to Molecular Mechanics and Quantum Chemical Calculations; Wavefunction, Inc.: Irvine, 1998.

[2] Computational Approaches in Supramolecular Chemistry (NATO Science Series C); Wipff, G., Ed.; Kluwer: Dordrecht, 1994.

[3] Beech, J.; Cragg, P. J.; Drew, M. G. B. J. Chem. Soc. 1994, 719.

[4] Vayssiere, P.; Wipff G. J. Phys. Chem. Chem. Phys. 2003, 5, 13. 
[5] Felix, V.; Matthews, S. E.; Beer, P. D.; Drew, M. G. B. Phys. Chem. Chem. Phys. 2002, 4, 3849.

[6] Mendes, A.; Bonal, C.; Morel-Desrosiers, N.; Morel, J. P.; Malfreyt, P. J. Phys. Chem. B, 2002, 106, 4516.

[7] Wipff, G. J. Coord. Chem. 1992, 27, 1.

[8] Cragg, P. J.; Drew, M. G. B.; Steed, J. W. Supramol. Chem. 1999, 11, 5.

[9] Sun, Y.; Kollman, P. A. J. Am. Chem. Soc. 1995, 117, 3599.

[10] Abouderbala, L. O.; Belcher, W. J.; Boutelle, M. G.; Cragg, P. J.; Steed, J. W.;

Turner, D. R.; Wallace, K. J. Proc. Natl. Acad. Sci. USA, 2002, 99, 5001.

[11] Liu, L.; Li, X.; Guo, Q. J. Mol. Struct. (Theochem) 2000, 530, 31.

[12] Wen, X.; Tan, F.; Jing, Z.; Liu, Z. J. Pharm. Biomed. Anal. 2004, 34, 517.

[13] Cooray, A. S.; de Silva, K. M. N. J. Mol. Struct. (Theochem) 2004, 678, 223.

[14] Pichierri, F. Chem. Phys. Letts. 2005, 403, 252.

[15] Gutsche, C. D. Calixarenes; Monographs in Supramolecular Chemistry;

Stoddart, J. F., Ed.; The Royal Society of Chemistry: Cambridge, 1989.

[16] Izatt, R. M.; Terry, R. E.; Haymore, B. L.; Hansen, L. D.; Dalley, N. K.;

Avondet, A. G.; Christensen, J. J. J. Am. Chem. Soc. 1976, 98, 7620.

[17] Miah, M.; Pavey, K. D.; Gun'ko, V. M.; Sheehan, R.; Cragg, P. J. Supramol. Chem. 2004, 16, 185.

[18] Ogden, M. I.; Rohl, A. L.; Gale, J. D. Chem. Commun. 2001, 1626.

[19] Fernández-Ramos, A.; Smedarchina Z.; Pichierri, F. Chem. Phys. Letts. 2001, 343, 627.

[20] Macias, A. T.; Norton, J. E.; Evanseck, J. D. J. Am. Chem. Soc. 2003, 125, 7620.

[21] Mäkinen, M.; Jalkanen, J.-P.;Vainiotalo, P. Supramol. Chem. 2005, 17, 377. 
[22] Backes, A. C.; Schatz, J.; Siehl, H-U. J. Chem. Soc. 2002, 2, 484.

[23] Joback, K. G.; Reid, R. C. Chem. Eng. Commun. 1987, 57, 233 as implemented by ChemDraw Ultra ${ }^{\circledR,}{ }^{\circledR}$ 1985-2000 CambridgeSoft.com.

[24] Lamb, M. L.; Jorgensen, W. L. Curr. Opin. Chem. Biol. 1997, 1, 449.

[25] Suzuki, K.; Minami, H.; Yamagata, Y.; Fujii, S.; Tomita, K.; Asfari, Z., Vicens, J. Acta Cryst. 1992, C48, 350.

[26] Masci, B. Tetrahedron, 1995, 51, 18.

[27] Sheehan, R. PhD thesis; University of Brighton, 2006.

[28] See Supplementary Material.

[29] Halgren, T. A. J. Comput. Chem. 1996, 17, 490.

[30] Armentrout, P. B. Int. J. Mass Spec. 1999, 193, 227.

[31] Izatt, R. M.; Bradshaw, J. S.; Nielsen, S. A.; Lamb, J. D.; Christensen, J. J.; Sen, D. Chem. Rev. 1985, 85, 271.

[32] Cragg, P. J. A Practical Guide to Supramolecular Chemistry; Wiley: Chichester, 2005.

[33] Alemán, C.; den Otter, W. K.; Tolpekina, T. V.; Briels, W. J. J. Org. Chem. 2004, $69,951$.

[34] See pp. 319-348 in reference 2.

[35] Lauterbach, M.; Wipff, G. in Physical Supramolecular Chemistry (NATO Science Series C); Echegoyan, L.; Kaifer, A. E., Eds; Kluwer: Dordrecht, 1996, pp. 65-102. [36] Mecozzi, S.; West, Jr., A. P.; Dougherty, D. A. Proc. Natl. Acad. Sci. USA 1996, 93, 10566.

[37] Re, S.; Nagase, S. Chem. Commun. 2004, 658.

[38] Tsuzuki, S.; Honda, K.; Uchimura, T.; Mikami, M.; Tanabe, K. J. Phys. Chem. A 1999, 103, 8265 . 
[39] Oki, M.; Takano, S.; Toyota, S. Bull. Chem. Soc. Jpn. 2000, 73, 2221.

[40] Mecozzi, S.; West, Jr. A. P.; Dougherty, D. A. J. Am. Chem. Soc. 1996, 118, 2307.

[41] Steed, J. W.; Atwood, J. L. Supramolecular Chemistry; Wiley: Chichester, 2000, pp. 21-25. 
Figure 1. Macrocycles investigated in this study.

Figure 2. Correlation between $\Delta \mathrm{H}_{\mathrm{f}}$ energies of macrocycles $\mathbf{1}$ to $\mathbf{9}$ calculated by PM3 and Joback methods (top) and total energies of macrocycles $\mathbf{1}$ to $\mathbf{9}$ calculated by $a b$ initio and Joback methods (bottom).

Figure 3. Guests bound by $\mathbf{1 0}$.

Figure 4. An example of conformational rearrangement: the $\mathbf{1 0 \cdot 1 3}$ complex showing initial constraints (top) and after geometry optimisation (bottom). Hydrogen atoms have been omitted for clarity.

Figure 5. Superimposition of the calculated HOMO and HOMO-1 on $\mathbf{1 0}$ indicating the cation binding region.

Figure 6. Correlation between LUMO (top) and electrostatic energies (bottom) with $\Delta \mathrm{G}^{\mathrm{o}}$ values for guests 11-17.

Table 1. $\Delta \mathrm{H}_{\mathrm{f}}$ and ab initio total energies for macrocycles $\mathbf{1}$ to 9

Table 2. Comparison of data for guest binding by $10 .{ }^{a}$ Data from ref. 26 . 
Figure 2

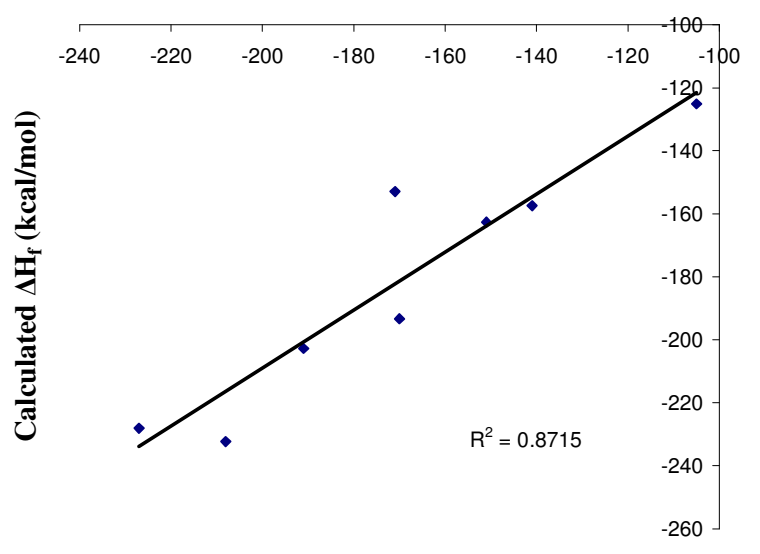

Joback method $\Delta \mathbf{H}_{\mathrm{f}}(\mathrm{kcal} / \mathrm{mol})$

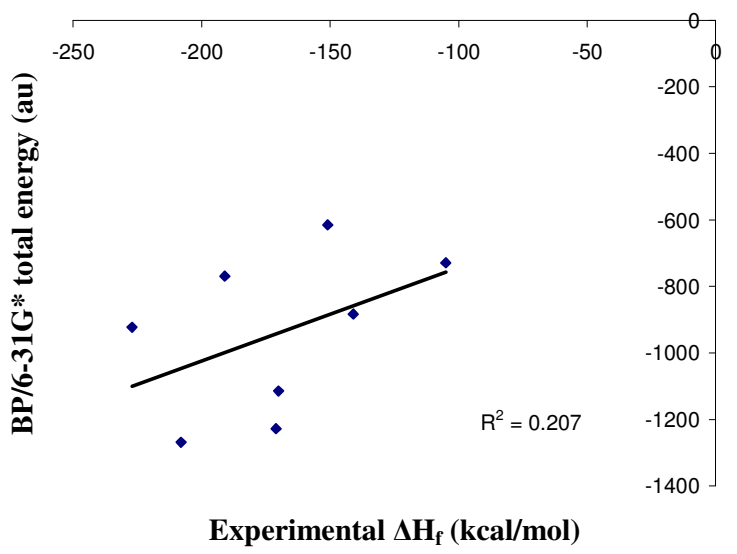

URL: http:/mc.manuscriptcentral.com/tandf/gsch Email: suprachem@mail.cm.utexas.edu 


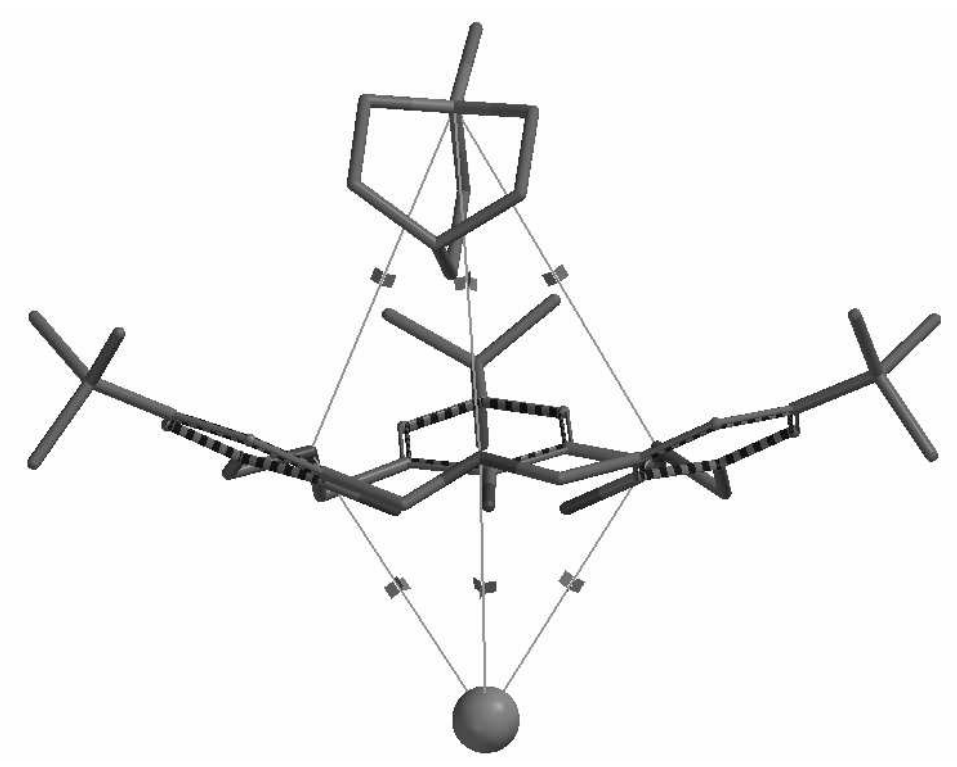

$268 \times 155 \mathrm{~mm}(96 \times 96 \mathrm{DPI})$ 


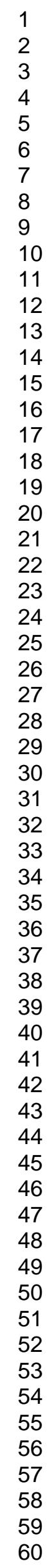

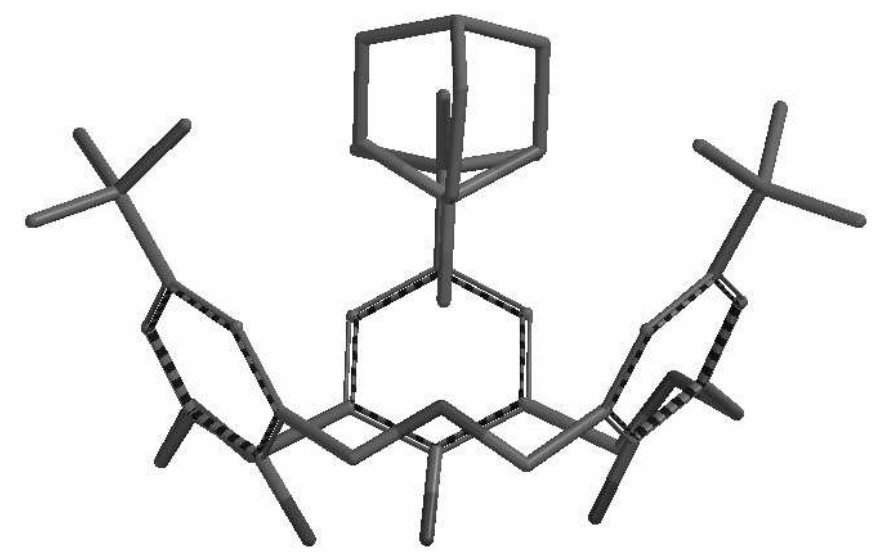

$268 \times 160 \mathrm{~mm}(96 \times 96$ DPI) 
1

2

3

4

5

6

7

8

9

10

11

12

13

14

15

16

17

18

19

20

21

22

23

24

25

26

27

28

29

30

31

32

33

34

35

36

37

38

39

40

41

42

43

44

45

46

47

48

49

50

51

52

53

54

55

56

57

58

59

60

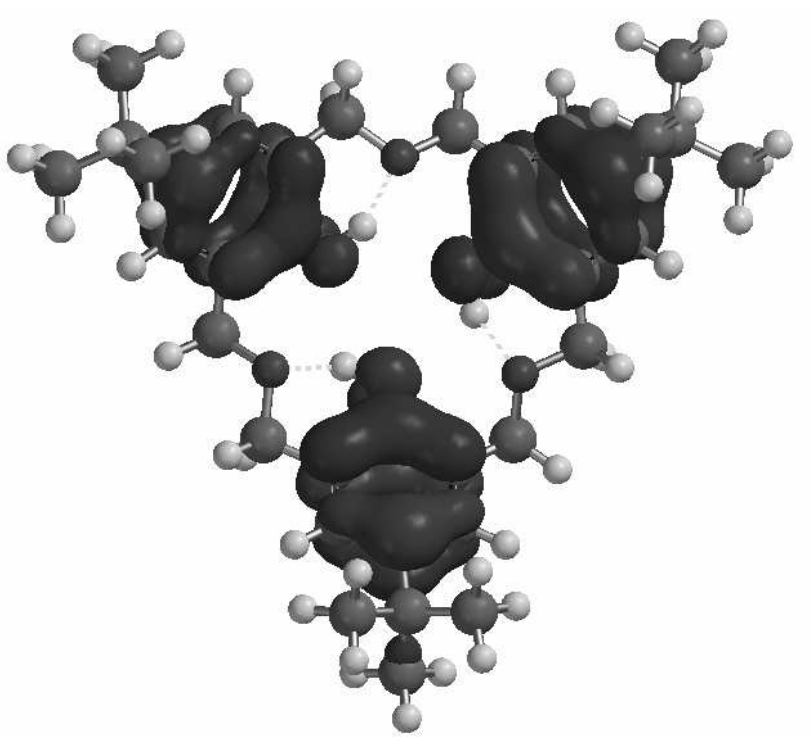

$268 \times 150 \mathrm{~mm}(96 \times 96 \mathrm{DPI})$ 
Figure 6.

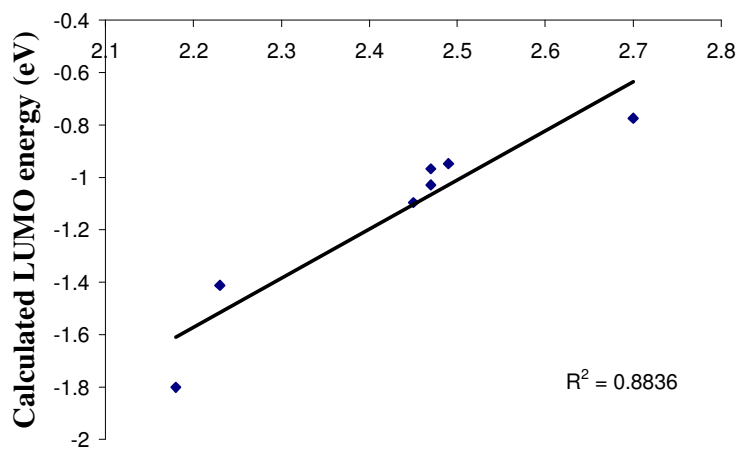

Experimental - $\Delta \mathrm{G}(\mathrm{kcal} / \mathrm{mol})$

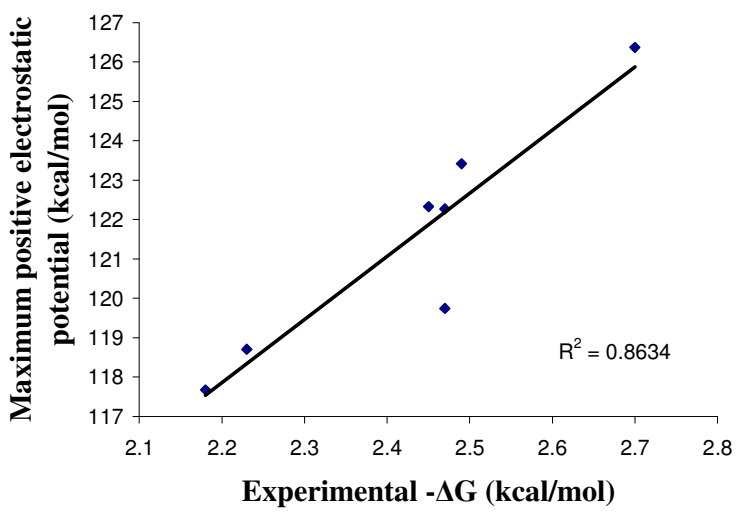


Table 1

\begin{tabular}{|c|c|c|c|c|c|}
\hline & \multicolumn{2}{|c|}{$\begin{array}{l}\Delta \mathrm{H}_{\mathrm{f}}(\mathrm{kcal} / \mathrm{mol}) \\
\text { obtained from: }\end{array}$} & \multicolumn{3}{|c|}{$\begin{array}{l}\text { Total energy (au) from single } \\
\text { point ab initio calculations } \\
\text { with basis set: }\end{array}$} \\
\hline & $\begin{array}{l}\text { Joback } \\
\text { method }\end{array}$ & PM3 & $\begin{array}{l}\mathrm{HF} / 3- \\
21 \mathrm{G}^{*}\end{array}$ & $\begin{array}{l}\mathrm{HF} / 6- \\
31 \mathrm{G}^{*}\end{array}$ & $\begin{array}{l}\mathrm{BP} / 6- \\
31 \mathrm{G}^{*}\end{array}$ \\
\hline 1 & -151 & -163.1 & -608.2 & -611.6 & -615.3 \\
\hline 2 & -191 & -203.7 & -760.3 & -764.5 & -769.1 \\
\hline 3 & -227 & -228.7 & -912.4 & -917.4 & -922.9 \\
\hline 4 & N/A & -283.6 & -1064.4 & -1070.3 & -1076.8 \\
\hline 5 & -141 & -157.4 & -872.9 & -877.8 & -883.2 \\
\hline 6 & -105 & -125.1 & -720.8 & -724.8 & -729.4 \\
\hline 7 & -171 & -152.9 & -1213.6 & -1220.4 & -1227.8 \\
\hline 8 & -170 & -193.3 & -1101.4 & -1107.5 & -1114.4 \\
\hline 9 & -208 & -232.3 & -1253.5 & -1260.4 & -1268.2 \\
\hline
\end{tabular}

URL: http:/mc.manuscriptcentral.com/tandf/gsch Email: suprachem@mail.cm.utexas.edu 
Table 2

\begin{tabular}{ccccc}
\hline & $\begin{array}{c}\text { LUMO } \\
(\mathrm{eV})\end{array}$ & $\begin{array}{c}\mathrm{ESP}(+\mathrm{ve}) \\
(\mathrm{kcal} / \mathrm{mol})\end{array}$ & $\begin{array}{c}\text { Cone } \\
\left.\text { angle }{ }^{\circ}\right)\end{array}$ & $\begin{array}{c}-\Delta \mathrm{G} \\
(\mathrm{kcal} / \mathrm{mol})^{\mathrm{a}}\end{array}$ \\
$\mathbf{1 1}$ & -0.947 & 123.4 & 75.1 & 2.49 \\
$\mathbf{1 2}$ & -0.775 & 126.4 & 67.4 & 2.70 \\
$\mathbf{1 3}$ & -1.029 & 119.7 & 61.7 & 2.47 \\
$\mathbf{1 4}$ & -1.096 & 122.3 & 71.1 & 2.45 \\
$\mathbf{1 5}$ & -0.968 & 122.3 & 69.2 & 2.47 \\
$\mathbf{1 6}$ & -1.413 & 118.7 & 67.4 & 2.23 \\
$\mathbf{1 7}$ & -1.801 & 117.7 & 96.2 & 2.18 \\
\hline
\end{tabular}




\title{
Supramolecular Chemistry In Silico
}

\author{
ROSEMARY SHEEHAN AND PETER J. CRAGG* \\ School of Pharmacy and Biomolecular Sciences, University of Brighton, Cockcroft \\ Building, Moulsecoomb, Brighton BN2 4GJ, UK
}

\section{Supplementary Material}

URL: http:/mc.manuscriptcentral.com/tandf/gsch Email: suprachem@mail.cm.utexas.edu 


\section{EXPERIMENTAL}

\section{Benchmarking}

Models of benzene, toluene, phenol, 4-methylphenol, 4-tert-butylphenol and pyridine were constructed (Spartan '04 for Windows) and optimised, first with molecular mechanics (MM+ forcefield in HyperChem and MMFF forcefield in Spartan), then with semi-empirical methods (PM3 algorithm). $\Delta \mathrm{H}_{\mathrm{f}}$ values were recorded, as was the average error for all models, and compared to values determined by the Joback method [1]. $\Delta \mathrm{H}_{\mathrm{f}}$ obtained from PC Spartan was then plotted against these values and a least squares regression line calculated. Single point $a b$ initio calculations were carried out for each structure at HF/3-21G*, HF/6-31G* and BP/6-31G* levels. The resulting total energies were recorded and a linear regression plotted for each versus $\Delta \mathrm{H}_{\mathrm{f}}$ values calculated by the Joback method.<smiles>c1ccccc1</smiles><smiles>Cc1ccccc1</smiles>

S1.1<smiles>Oc1ccccc1</smiles>

S1.2<smiles>Cc1ccc(O)cc1</smiles>

S1.4<smiles>CC(C)(C)c1ccc(O)cc1</smiles>

S1.5<smiles>c1ccncc1</smiles>

S1.6

Figure S1. Schematic representations of benzene (S1.1), toluene (S1.2), phenol (S1.3), 4-methylphenol (S1.4), 4-tert-butylphenol (S1.5) and pyridine (S1.6) 
1

2

3

\begin{tabular}{|l|c|c|c|c|c|c|c|}
\hline \multirow{2}{*}{ Model } & \multicolumn{6}{|c|}{$\Delta \mathrm{H}_{\mathrm{f}}(\mathrm{kcal} / \mathrm{mol})$ obtained from: } \\
\cline { 2 - 8 } & \multirow{2}{*}{ Joback method } & \multicolumn{3}{|c|}{ HyperChem 6.03 } & \multicolumn{3}{c|}{ Spartan '04 } \\
\cline { 2 - 8 } S1.1 & 19.8 & 23.292 & 21.868 & 21.216 & 23.454 & 22.022 & 21.324 \\
\hline S1.2 & -23 & -21.849 & -22.408 & -26.779 & -21.672 & -22.248 & -26.671 \\
\hline S1.3 & 12 & 13.912 & 14.225 & 13.429 & 14.091 & 14.41 & 13.569 \\
\hline S1.4 & -29.9 & -31.115 & -29.979 & -34.677 & -30.927 & -29.795 & -34.542 \\
\hline S1.5 & -48 & -43.884 & -40.885 & -32.738 & -43.572 & -40.585 & -32.536 \\
\hline S1.6 & 33 & 30.225 & 31.9 & 28.707 & 30.368 & 32.039 & 28.817 \\
\hline \multicolumn{2}{|c|}{ Average error } & 2.44 & 2.2 & 5.16 & 2.53 & 2.31 & 5.18 \\
\hline
\end{tabular}

Table $\mathrm{S} 1 . \Delta \mathrm{H}_{\mathrm{f}}$ values from the Joback method and from a range of semi-empirical calculations performed in HyperChem 6.03 and Spartan '04

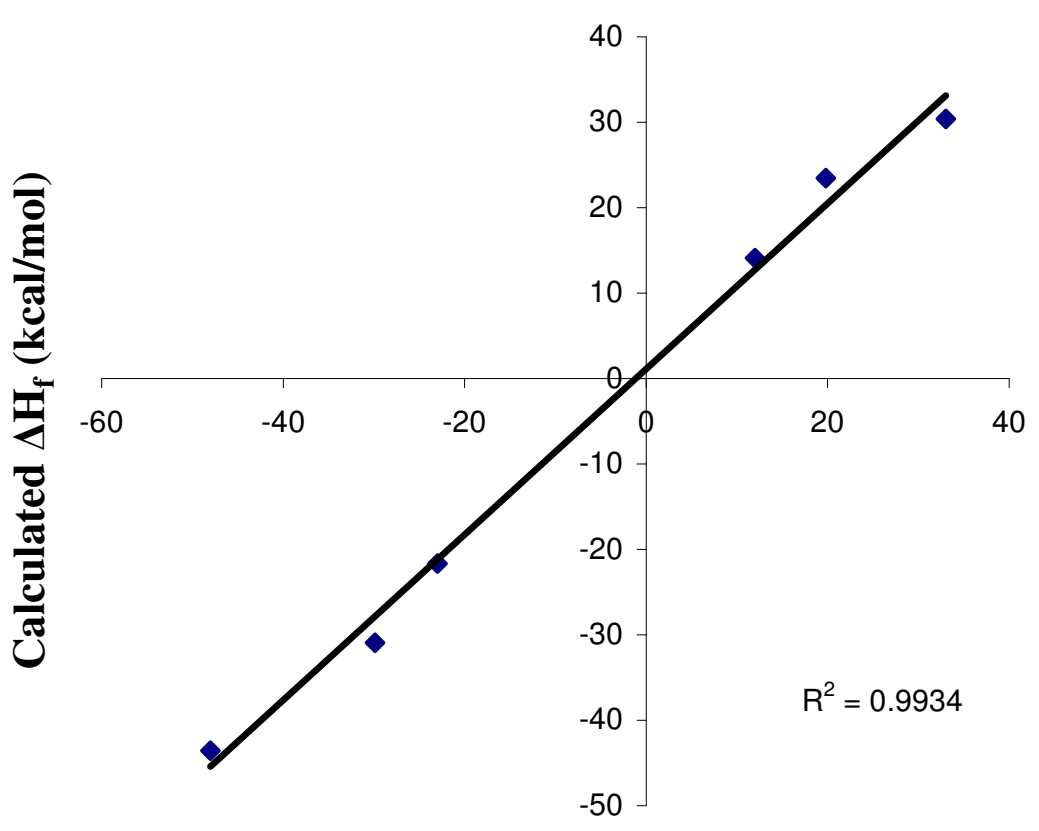

Joback method $\Delta \mathbf{H}_{\mathrm{f}}(\mathrm{kcal} / \mathrm{mol})$

Figure S2. Aromatic systems: PM3 heats of formation vs. $\Delta \mathrm{H}_{\mathrm{f}}$ values (Joback method) 


\begin{tabular}{|l|c|c|c|c|}
\hline \multirow{2}{*}{ Model } & \multirow{2}{*}{$\begin{array}{c}\Delta \mathrm{H}_{\mathrm{f}}(\mathrm{Joback} \\
\text { method, kcal/mol })\end{array}$} & \multicolumn{3}{|c|}{ Total energy (au) from single point ab initio calculations } \\
\cline { 3 - 5 } & 19.8 & -229.417049 & -230.701444 & -232.237343 \\
\hline S1.1 & -23 & -303.855533 & -305.555389 & -307.458097 \\
\hline S1.2 & 12 & -268.237053 & -269.737716 & -271.551946 \\
\hline S1.3 & -29.9 & -342.674635 & -344.590609 & -346.771766 \\
\hline S1.4 & -48 & -459.130763 & -461.687667 & -464.700478 \\
\hline S1.5 & 33 & -245.307975 & -246.690771 & -248.278910 \\
\hline S1.6 & & & & HF/6-31G* \\
\hline
\end{tabular}

Table $\mathrm{S} 2 . \Delta \mathrm{H}_{\mathrm{f}}$ values (Joback method) and from a range of ab initio calculations performed in Spartan '04

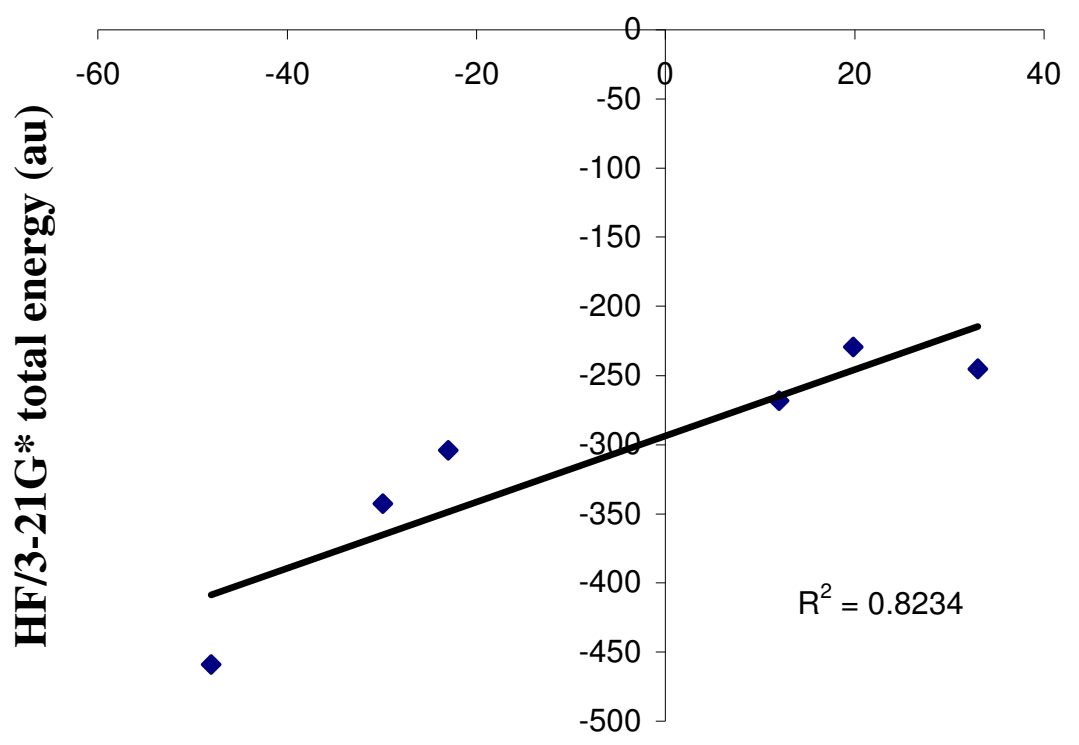

Joback method $\Delta \mathbf{H}_{\mathrm{f}}(\mathrm{kcal} / \mathrm{mol})$

Figure $\mathrm{S} 3 . \mathrm{HF} / 3-21 \mathrm{G}^{*}$ total energy correlation with $\Delta \mathrm{H}_{\mathrm{f}}$ values (Joback method) for benchmarking aromatic systems 


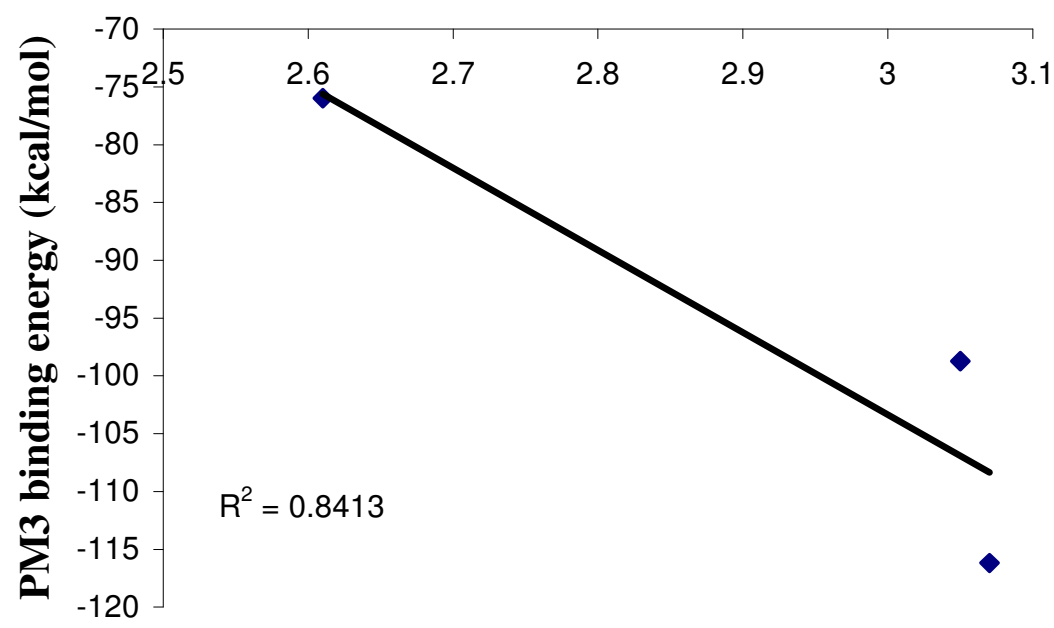

Experimental bond dissociation energy (eV)

Figure S4. Experimental bond dissociation energy (gas phase) vs. PM3 calculated binding energy (gas phase) for $\mathbf{1} \cdot \mathrm{Na}^{+}, \mathbf{2} \cdot \mathrm{Na}^{+}$and $\mathbf{3} \cdot \mathrm{Na}^{+}$.

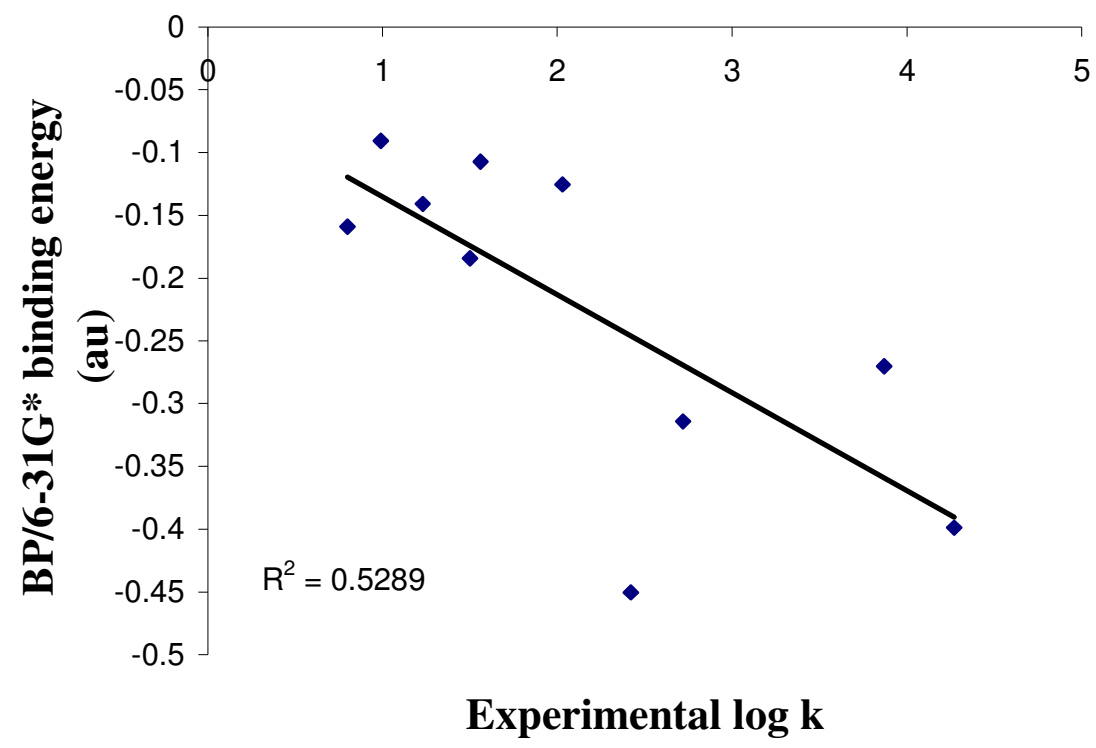

Figure S5. Experimental log k (aqueous) correlation with BP/6-31G* binding energy (gas phase) for complexes of ten cations with 3 [2]. 


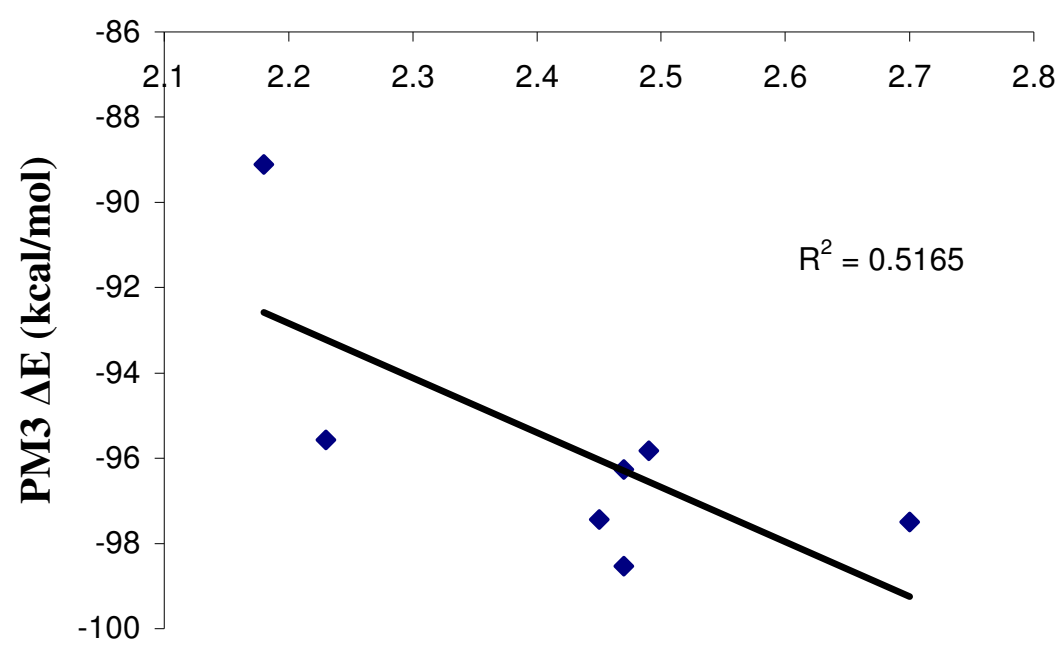

$-\Delta G(\mathrm{kcal} / \mathrm{mol})$

Figure S6. Gas phase PM3 binding energy correlation with experimental $-\Delta \mathrm{G}\left(\mathrm{CDCl}_{3}\right)$ for complexes of $\mathbf{1 0}$ [3].

\begin{tabular}{|c|c|c|c|c|}
\hline \multicolumn{2}{|c|}{$\begin{array}{l}\Delta \mathrm{H}_{\mathrm{f}}(\mathrm{kcal} / \mathrm{mol}) \\
\text { obtained from: }\end{array}$} & \multicolumn{2}{c|}{$\begin{array}{c}\text { Total energy (au) from } \\
\text { geometry optimised } a b \\
\text { initio calculations }\end{array}$} \\
\hline & $\begin{array}{c}\text { Joback } \\
\text { method }\end{array}$ & PM3 & HF/3-21G* & HF/6-31G* \\
\hline $\mathbf{1}$ & -151 & -163.1 & -608.3 & -611.6 \\
\hline $\mathbf{2}$ & -191 & -203.7 & -760.3 & -764.6 \\
\hline $\mathbf{3}$ & -227 & -228.7 & -912.4 & -917.5 \\
\hline $\mathbf{4}$ & $\mathrm{N} / \mathrm{A}$ & -283.6 & -1064.5 & -1070.4 \\
\hline $\mathbf{5}$ & -141 & -157.4 & -872.9 & -877.8 \\
\hline $\mathbf{6}$ & -105 & -125.1 & -720.9 & -724.9 \\
\hline $\mathbf{7}$ & -171 & -152.9 & -1213.7 & -1220.4 \\
\hline $\mathbf{8}$ & -170 & -193.3 & -1101.5 & -1107.6 \\
\hline $\mathbf{9}$ & -208 & -232.3 & -1256.6 & -1260.5 \\
\hline
\end{tabular}

Table S3. $\Delta \mathrm{H}_{\mathrm{f}}$ and ab initio energies for macrocycles 1 to $9\left(\mathrm{r}^{2}=0.2078\right.$ [Joback $v s$. $\left.\mathrm{HF} / 3-21 \mathrm{G}^{*}\right] ; \mathrm{r}^{2}=0.2073$ [Joback vs. HF/6-31G*]).

[1] Joback, K. G.; Reid, R. C. Chem. Eng. Commun., 1987, 57, 233 as implemented by ChemDraw Ultra $^{\circledR}{ }^{\circledR}$ 1985-2000 CambridgeSoft.com

[2] Izatt, R. M.; Bradshaw, J. S.; Nielsen, S. A.; Lamb, J. D.; Christensen, J. J.; Sen, D. Chem. Rev. 1985, 85, 271.

[3] Masci, B. Tetrahedron, 1995, 51, 18.

UR': http:/mc.manuscriptcentral.com/tandf/gsch Email: suprachem@mail.cm.utexas.edu 